\title{
Paper: Attendance and Social Interdependence in Game Development Labs
}

\section{Brantly Edward McCord, Purdue Polytechnic Institute}

Brantly McCord is a teaching assistant and co-instructor at Purdue Polytechnic Institute assisting with the development and instruction of video game dev curriculum. His instructional specialties are in Unreal Engine 4, visual scripting and art design, and his current research interests are concentrated on education in his field.

\section{Dr. Ronald Erdei, University of South Carolina}

Dr. Ronald Erdei is an Assistant Professor of Computer Science at the University of South Carolina Beaufort. A graduate of Purdue University (PhD 2016), his research focuses primarily on reducing barriers to the learning process in college students. Topics of interest include computer science pedagogy, collaborative learning in college students, and human-centered design. Of particular interest are the development and application of instructional practices that provide benefits secondary to learning (i.e., in addition to learning), such as those that facilitate in learners increased self-efficacy, increased retention/graduation rate, increased matriculation into the workforce, and/or development of professional identity.

\section{Dr. David M Whittinghill, Purdue University-Main Campus, West Lafayette (College of Engineering)}

Dr. David Whittinghill is an Associate Professor of Computer Graphics Technology and Computer and Information Technology. Dr. Whittinghill's research focuses on gaming, simulation and computer programming education and how these technologies can more effectively address outstanding issues in health, education, and society. Dr. Whittinghill leads projects in pediatric physical therapy, sustainable energy simulation, Chinese language learning, virtual reality, and games as a tool for improving educational outcomes. Dr. Whittinghill is the director of the Games Innovation Laboratory (www.gamesinnovation.org).

\section{Dr. Marisa Exter, Purdue University at West Lafayette}

Marisa Exter is an Assistant Professor of Learning Design and Technology in the College of Education at Purdue University. Dr. Exter's research aims to provide recommendations to improve or enhance university-level design and technology programs (such as Instructional Design, Computer Science, and Engineering). Some of her previous research has focused on software designers' formal and non-formal educational experiences and use of precedent materials, and experienced instructional designers' beliefs about design character. These studies have highlighted the importance of cross-disciplinary skills and student engagement in large-scale, real-world projects.

Dr. Exter currently leads an effort to evaluate a new multidisciplinary degree program which provides both liberal arts and technical content through competency-based experiential learning. 


\title{
Attendance and social interdependence in game development labs.
}

\begin{abstract}
This is an exploratory research study aimed toward steadying attendance across a semester of higher education video game development labs with attention to cooperation as a co-factor. Following the observation of unusually strong attendance in a highly cooperative game development lab class which aligns with these theories, this paper seeks to explore whether subfactors of positive social interdependence are co-factors with lab attendance. Sparked by previous case data, this exploratory study examines data from the Fall 2019 iteration of the introductory video game development course, defining and measuring potential co-factor variables during an individual-focused half of the course supplemented with group activity, and a fully group-focused half of the semester, with future interest in investigating a correlation between attendance and positive interdependence. Empirical studies of both the performance impact of attendance, and the financial reliance of residential higher education institutions on student attendance and retention suggest that understanding how to operationalize students' motivation to attend class is epistemically and fiscally valuable. Studies of positive interdependence raise interest as a co-factor contextually through high commitment, joint efficacy, and mutual benefit, strongly overlapping with empirical antecedents of higher education retention and seminal social psychological frameworks. Therefore, the author began an intended extensive analysis of consecutive semesters. All students enrolled in the Fall 2019 introductory game development course ( $\mathrm{n}=56$ for students with matched data sets, 59 retained participant students total) were engaged in cooperatively-designed lectures and lab activities, with the first half of the semester's lighter collaborative activity and independent assigned work to be compared to the second half's full-time group project work. Between these designed halves, two null hypotheses were assessed: 1) lab attendance in the first half of the semester is equivalent to the second half, and 2) subfactors of positive interdependence in the first half of the semester are equivalent to the second half. Attendance proportions and surveyed positive interdependence measures for the Fall 2019 semester were analyzed using paired sample t-tests. Attendance, and a majority of positive interdependence subfactors, were not significantly different across halves of the semester, suggesting that collaboration had evened results across the whole, though not all effects reached their target effects. The Classroom Life Instrument was used to formally measure the presence of a positive interdependent context before and after group project work.
\end{abstract}




\section{Introduction}

According to studies of student retention, and attendance in higher education, social integration of students is pivotal in their ability to persist to graduation [1]. The theory of social interdependence [2], [3] elaborates that inclusive, cooperative work is characterized by students being highly committed. During the Fall 2017 semester of Purdue Polytechnic Institute's introductory video game development course (CGT Game Dev I), a course design emphasizing collaboration among students was employed; an extremely collaborative atmosphere and an unusually high lab attendance rate was then observed. The following year (Fall 2018), the design of CGT Game Dev I was altered to emphasize a more individualized curriculum; decreased attendance was then observed until end-of-semester groupwork began [4].

The problem addressed by this project is that variable co-factors for unusually high attendance rates in higher education laboratory classes are not well defined enough to operationalize.

The purpose of this project is to investigate the equivalence of attendance and positive interdependence subfactors in two collaborative activity treatments in an introductory video game development course, as well as the effect of positive interdependence subfactors as a potential co-factor variable to lab attendance. The research questions and hypotheses posed are:

- RQ1) Is lab attendance proportionally equivalent between the first half and second half of the semester?

○ $\mathrm{HO}_{1}$ : Lab attendance in the first half of the semester is equivalent to the second half.

$\mathrm{HA}_{1}$ : Lab attendance in the first half of the semester is not equivalent to the second half.

- RQ2) Is positive interdependence equivalent between the first half and second half of the semester?

$\circ \mathrm{HO}_{2 \mathrm{~A}}$ : Cooperative learning in the first half of the semester is equivalent to the second half.

$\mathrm{HA}_{2 \mathrm{~A}}$ : Cooperative learning in the first half of the semester is not equivalent to the second half.

○ $\mathrm{HO}_{2 \mathrm{~B}}$ : Positive goal interdependence in the first half of the semester is equivalent to the second half.

$\mathrm{HA}_{2 \mathrm{~B}}$ : Positive goal interdependence in the first half of the semester is not equivalent to the second half.

- $\mathrm{HO}_{2 \mathrm{C}}$ : Resource interdependence in the first half of the semester is equivalent to the second half.

$\mathrm{HA}_{2 \mathrm{C}}$ : Resource interdependence in the first half of the semester is not equivalent to the second half.

- $\mathrm{HO}_{2} \mathrm{D}$ : Instructor academic support in the first half of the semester is equivalent to the second half.

$\mathrm{HA}_{2 \mathrm{D}}$ : Instructor personal support in the first half of the semester is not equivalent to the second half.

$\circ \mathrm{HO}_{2 \mathrm{E}}$ : Student personal support in the first half of the semester is equivalent to the second half. 
$\mathrm{HA}_{2 \mathrm{E}}$ : Student academic support in the first half of the semester is not equivalent to the second half.

- $\mathrm{HO}_{2 \mathrm{~F}}$ : Student academic support in the first half of the semester is equivalent to the second half.

$\mathrm{HA}_{2 \mathrm{~F}}$ : Student academic support in the first half of the semester is not equivalent to the second half.

- $\mathrm{H}_{2 \mathrm{G}}$ : Student personal support in the first half of the semester is equivalent to the second half.

$\mathrm{HA}_{2 \mathrm{G}}$ : Student personal support in the first half of the semester is not equivalent to the second half.

- $\mathrm{H}_{2 \mathrm{H}}$ : Class cohesion in the first half of the semester is equivalent to the second half.

$\mathrm{HA}_{2 \mathrm{H}}$ : Class cohesion in the first half of the semester is not equivalent to the second half.

- $\mathrm{HO}_{21}$ : Fairness of grading in the first half of the semester is equivalent to the second half.

$\mathrm{HA}_{2 \mathrm{I}}$ : Fairness of grading in the first half of the semester is not equivalent to the second half.

- $\mathrm{HO}_{2 \mathrm{~s}}$ : Achieving for social approval in the first half of the semester is equivalent to the second half.

$\mathrm{HA}_{2 \mathrm{~J}}$ : Achieving for social approval in the first half of the semester is not equivalent to the second half.

- $\mathrm{HO}_{2 \mathrm{~K}}$ : Academic self-esteem in the first half of the semester is equivalent to the second half.

$\mathrm{HA}_{2 \mathrm{~K}}$ : Academic self-esteem in the first half of the semester is not equivalent to the second half.

- $\mathrm{H}_{2 \mathrm{~L}}$ : Alienation in the first half of the semester is equivalent to the second half. $\mathrm{HA}_{2 \mathrm{~L}}$ : Alienation in the first half of the semester is not equivalent to the second half.

- RQ3) Is positive interdependence associated with lab attendance?

- $\mathrm{H}_{3}$ : Positive interdependence is not proportionally related with lab attendance. $\mathrm{HA}_{3}$ : Positive interdependence is proportionally related with lab attendance.

It is not uncommon for researchers to explore the factors and rationale behind absenteeism in higher education [5], [6], as research on attendance reveals that it improves performance outcomes in and out of compulsory circumstances with some results appearing indecisive at a grand level [7] - [9]. However, should research be believed that absentee behavior may be due to rational decision-making, the gap in research on the inverse - the drive to attend - appears more clearly. Kottasz [5] outlined that a student's decision to attend schooling depends on both the ability and the motivation to attend, and in the case of the latter, additional research is sought.

As students in higher education video game development will form interdisciplinary teams for major projects, analogous (albeit at a smaller scale) to those in industry careers [10], and only a limited number of interactive lab sessions may occur before these teams form, every moment 
counts for students to be able to synchronously meet, familiarize with each other, and form productive subcultural bonds.

Social psychological foundations [11], [12], in-situ epistemological theory [13], [14], interactionalist theory [1], [15] - [17] as well as insights into the impact of motivation [5] and social belonging [18] have paved a groundwork for the viability of positive social interdependence (cooperation) [3] as a co-factor of student commitment and retention in their holistic group of classroom learners. Yet, satisfactory research concurrence in this interdependent intersection has not yet been achieved in specialized, collaborative career focused domains of education, and much research on higher education attendance faces substantial limitations [6] or elects to seek understanding beneath attendance behaviors [5].

Social interdependence posits that individuals' outcomes depend on the action and interference of others. Interacting - simultaneously or sequentially acting contingently with others - can drive the attainment of joint goals or obstruct them [19]. Individuals' attendance and participation in a group situation affords interaction, and the binding nature of this interaction bolsters dependence on one another, positively or negatively [3]. Social interdependence has been in steady use and under study in the early-2000s [19] with over 1,200 studies whose data register a validating effect size [20].

Social interdependence may be used as a framework to address the motivation of individuals [21] with some precedent in cultivating positive collaborative interaction in higher education [22], a target interest of this study. To engage such a framework, it must be acknowledged that context readily affects the motivation being framed [3]. Johnson and Johnson [3] clarify that the positive or negative context of social interdependence (and thereby its effect) is identified by way of the following considerations:

(1) the value or benefit of the goal (i.e. mutual benefit, differential benefit or selfbenefit); (2) the perceived ability to achieve the goal (i.e. joint, differential, self-efficacy); (3) intrinsic and extrinsic motivation; (4) epistemic curiosity and continuing motivation; and (5) commitment to succeed [3].

These attributes are used to differentiate between three different context-driven motivational codes [3]. Positive interdependence, also referred to as cooperation, is identified via benefits and efficacy shared in the group, curiosity stimulated by opposing viewpoints, an internal source of motivation, and high commitment to the group. As this study seeks to investigate whether collaborative group work reliably forms a high-commitment, accountable atmosphere as seen in Fall 2017 [23], Johnson and Johnson's positive interdependence is the most appropriate motivational mode to pursue [3]. Of the three contextual codes, positive interdependence is the only one marked by high commitment of an individual in a group, and its exclusive shared properties appear to serve a group's members well. 


\section{Methods}

This exploratory study analyzes data from the Purdue Polytechnic Institute's Fall 2019's sixteenweek CGT Game Dev I course. All Fall 2019 CGT Game Dev I students retained in the course, who were sophomores or beyond, were considered participants, though due to unforeseen technical difficulties in survey distribution and some student non-responsiveness, not every retained student's results were analyzed $(n=56)$; all students belonged in the same group, without a control comparison due to existing limitations of sample size and length of study.

Timeline of Fall 2019 CGT Game Dev I Procedures to Analyze

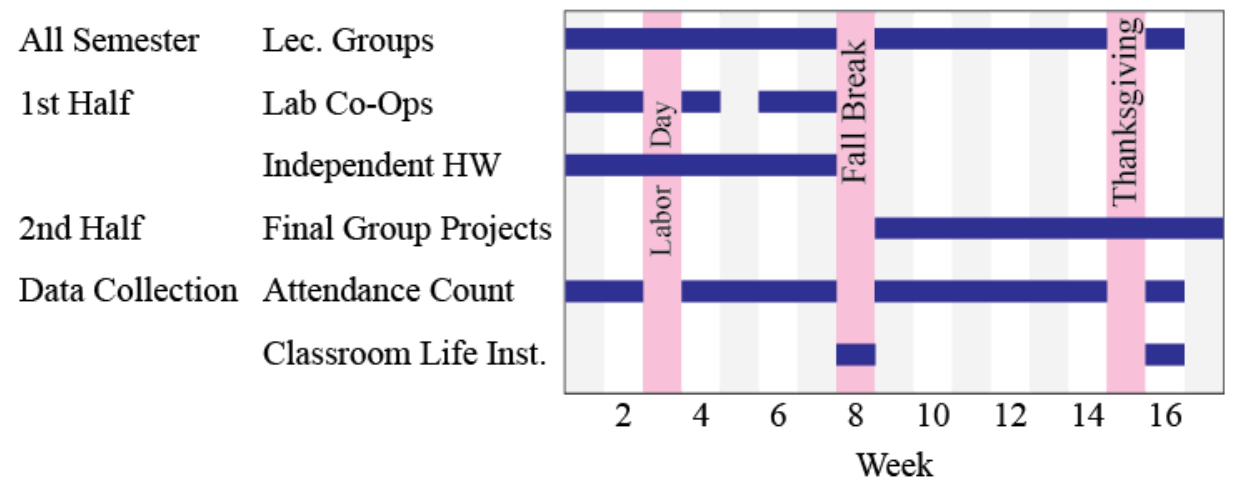

Figure 1. Gantt chart depicting the modes of work throughout the semester and when relevant data was collected.

On the first day of lab, students were told the attendance policy: every student was allotted one free unexcused absence without question, and any additional unexcused absences subtracted ten grade points from their total grade. Excused absences included documented illnesses, grievous or emergency family situations (e.g. death in the family), conflicting professional appointments or visitations (e.g. medical checkup, career fair attendance, interviews), and exceptions outlined by student disability forms made known to one or more class instructors. A student who arrived at class, no matter how late, was not considered absent, though they were marked as late as a data category for potential future study. Students who missed lab in the first and second week were sent an email reinforcing the attendance policy, stating that they had used their one free absence, and that further absences may result in lost points. During week 8 and 9, all students were reminded that their attendance is graded and mandatory to dissolve the misunderstanding of an inquisitive student who assumed final project work would be performed outside of lab classes with optional attendance, which foreseeably may have affected attendance rates in that time period.

Collaborative lecture and lab activities were facilitated each week to foster positive interdependence (barring week 3's lab due to Labor Day and week 5's lab due to unexpected time limitations) (see Figure 1). Group lecture activities always occurred in the second of two lecture sessions each week, engaging large groups of nine to twelve or small groups of two to four students with various brainstorming and documentation activities. For instance, in week 1, 
lecture instructors and participating upperclassmen mentors facilitated large groups in order to conceptualize the hypothetical work required to create an existing game, using an image of the game as visual reference; other activities had students form their final project groups early and begin preproduction of their project, documenting concepts and expected parameters of their upcoming work.

For nearly each lab session before final project work weeks, a Co-Opportunity (Co-Op) activity was performed in the last ten minutes of class, in which small groups of two to four students would answer three to four open-ended questions based on the lab session's topic and learnings. Students wrote their answers on a class-wide shared Google Doc such that each team could see each other's answers above or below theirs, while the teaching assistant would occasionally make supportive comments while walking around the room. The first three Co-Ops in lab week 1,2 , and 4, used randomized groups, and week 6 and 7 used the final project groups that students formed in their lecture activities. In order to cultivate a cooperative, motivational context, tenets of social interdependence were structured into each question [3].

Beginning in week 9, halfway through the semester, lab sessions were dedicated to students working in their final project groups, meeting with a dedicated upperclassmen mentor to negotiate and assign individual game development tasks for the mutual game project; each team also met with the teaching assistant in order to grade attendance, to grade completeness of any tasks assigned the week before, and to receive help with technical problems. Final project tasks were graded individually each week, but the whole group received an identical grade for the final submitted product.

Measurement of positive interdependence, as well as assessment of its measurement instrument, has been rigorously performed by its proponents. The Classroom Life Instrument was published by researchers David Johnson, Roger Johnson, and Douglas Anderson [24], surveying 859 students (grades 4 through 9) at the classroom level with 59 five-point Likert scale questions, designed to evaluate the impact of numerous measures of cooperation and including Cronbach alpha values of internal reliability for reference. The 1983 iteration of the Classroom Life Instrument was selected for its wording of questions to the subjects being studied, as well as recent review concerning its field use [25] and convenience of access. Measures of competition and individualistic codes of social interdependence are not included, as deemed not necessary for this study: classroom research of the tool has demonstrated little overlap between these contextual modalities, such as cooperation and competition [26], thus likelihood of mixed motivations are expected to be minimal.

The Classroom Life Instrument [24] was distributed to students in week 8 and week 16. It features 59 unique 5-point Likert scale questions, meant to measure the level of positive interdependence achieved in the class [24]. Minor alterations have been made to the wording of questions for appropriateness: "instructors" replaces "teacher; "assigned work" replaces "assignment"; "work" replaces "schoolwork"; "they" replaces "he/she" accordingly; 
"parents/guardians" replaces "parents." Two questions have also been removed, as they do not apply to grading methods in the course. An additional note precedes the survey stating that "group" should holistically reference the group work and partner activities performed throughout CGT Game Dev I.

Variables delivered for analysis in this study include data from the Fall 2019 iteration of CGT Game Dev I lab: lab attendance proportions from weekly lab roll calls and positive interdependence scores using the Classroom Life Instrument [24]. The analytical goal of this research is to investigate the equivalence of attendance between the first half (independent work and Co-Ops in lab) and second half (full group project work in lab) of the semester, to identify whether the collaborative activities of each half are similar in effect. To analyze the maintenance of lab attendance across both treated halves of the semester, a paired sample t-test of each student's attendance proportion from the first half and second half of the semester was conducted with a confidence level of $95 \%(\alpha=0.05)$; similarly, to determine the equivalence of positive interdependence for both treated halves, a paired sample t-test of each student's positive interdependence subscale scores (e.g. cooperative learning, positive goal interdependence) from the Classroom Life Instrument was conducted, also with a confidence level of $95 \%(\alpha=0.05)$.

Due to limitations - the constrained meaningfulness of attendance variance between two eightweek periods, and the analysis of positive interdependence factors that have not been extensively reviewed in this paper-it is expected that these results will serve as a step toward more complete understanding following longitudinal replication.

\section{Results}

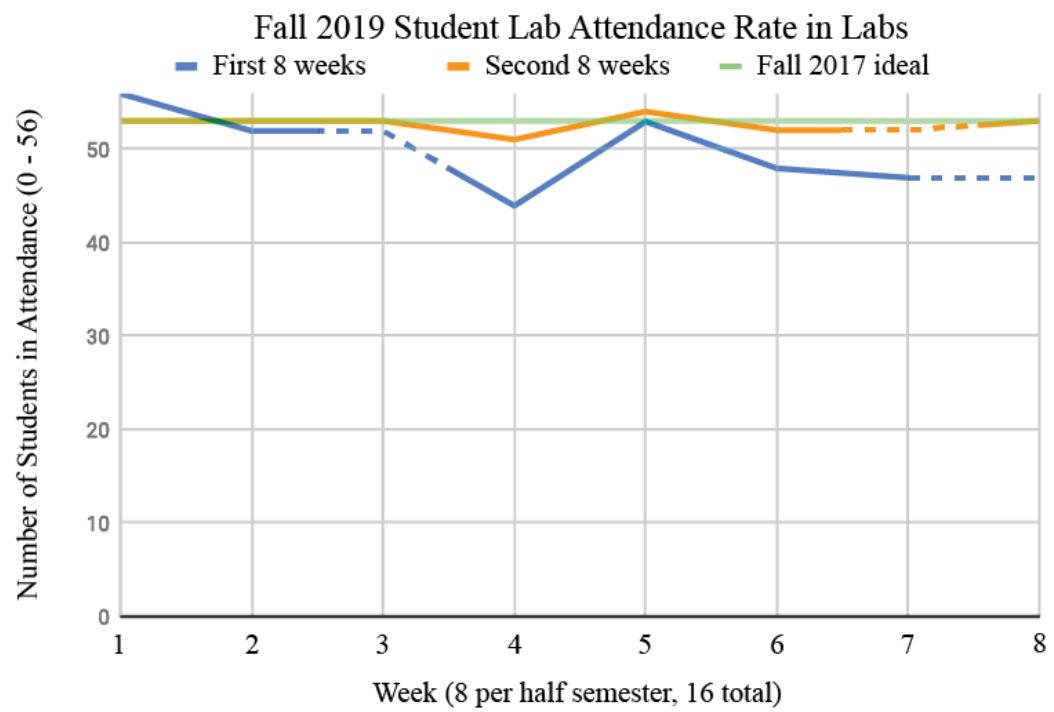

Figure 2. This graph visualizes the attendance patterns of game development students $(\mathrm{n}=56)$ across two halves of the semester. Dotted lines display when attendance was not collected due to mandatory break days: Labor Day on week 3 and Fall Break on week 8 of the first 8 weeks, and Thanksgiving Break on week 7 of the second 8 weeks (week 15 overall). Due to inconsistency between days to attend across halves, data was analyzed proportionally. A line scaled to proportion shows the ideal high values pursued from the Fall 2017 semester of interest. 
Table 1: Proportional Lab Attendance t-test

\begin{tabular}{lllll}
\hline Test subfactor & H1 Avg & H2 Avg & p value & Intended result? \\
\hline Attendance & 0.892857 & 0.938776 & 0.055 & Yes
\end{tabular}

The paired sample t-test of average, proportional attendance in the first and second halves of the semester did not yield significant results by a slight margin ( $\mathrm{p}=0.055)$, suggesting that students' overall lab attendance in the individual-focused and group-focused halves of the semester did not significantly differ, and is worth investigating further for reasonable underlying subfactors and refinement of operations (see Table 1). Like the Fall 2017 semester of inspiration, lab attendance steadied and generally improved in the second half of the semester, during compulsory groupwork (see Figure 2).

Table 2: Classroom Life Instrument Survey Positive Interdependence t-tests

\begin{tabular}{llllll}
\hline $\begin{array}{l}\text { Pos Interdependence } \\
\text { Subfactor }\end{array}$ & $\begin{array}{l}\text { Cronbach's } \\
\text { alpha value }\end{array}$ & H1 Avg & H2 Avg & p value & Insignificance? \\
\hline *Cooperative learning & 0.83 & 4.356293 & 4.487245 & $* 0.035$ & $*$ No \\
\hline $\begin{array}{l}\text { Positive goal } \\
\text { interdependence }\end{array}$ & 0.61 & 4.202381 & 4.327381 & 0.184 & Yes \\
\hline Resource interdependence & 0.74 & 4.130357 & 4.239286 & 0.257 & Yes \\
\hline Teacher academic support & 0.78 & 4.504464 & 4.629464 & 0.063 & Yes \\
\hline Teacher personal support & 0.80 & 4.227679 & 4.361607 & 0.124 & Yes \\
\hline Student academic support & 0.67 & 4.066964 & 4.209821 & 0.100 & Yes \\
\hline *Student personal support & 0.78 & $* 3.921429$ & 4.035714 & 0.221 & Yes \\
\hline *Class cohesion & 0.51 & $* 3.653571$ & $* 3.739286$ & 0.266 & Yes \\
\hline Fairness of grading & 0.61 & 4.221429 & 4.339286 & 0.099 & Yes \\
\hline **Achieving for social & 0.72 & $* 2.935714$ & $* 3.253571$ & $* 0.012$ & $*$ No \\
approval & & & & & \\
\hline *Academic self-esteem & 0.61 & $* 3.425000$ & $* 3.582143$ & 0.093 & Yes \\
\hline *Alienation & 0.68 & $* 2.520455$ & $* 2.542208$ & 0.785 & Yes \\
\hline
\end{tabular}

* denotes failure of one or more research goals: subscale a) did not receive a score of $>4(<2$ for alienation) and/or b) was significantly different between halves of the semester

Ten of the twelve subfactors of positive interdependence did not yield significant results, suggesting that the individual and group-focused halves of the semester did not significantly differ, and are therefore worth further scrutiny (see Table 2): positive goal interdependence $(\mathrm{p}=0.184)$, resource interdependence $(\mathrm{p}=0.257)$, teacher academic support $(\mathrm{p}=0.063)$, teacher personal support ( $\mathrm{p}=0.124)$, student academic support $(\mathrm{p}=0.100)$, student personal support $(\mathrm{p}=0.221)$, class cohesion $(\mathrm{p}=0.266)$, fairness of grading $(\mathrm{p}=0.099)$, academic self-esteem $(\mathrm{p}=0.093)$, and alienation $(\mathrm{p}=0.785)$. Of these matched subfactors, resource interdependence, teacher academic support, teacher personal support, and student personal support had sufficient Cronbach alpha values of internal validity $(\alpha \geq 0.7)$ from the survey's initial testing [24]. Student 
personal support, class cohesion, achieving for social approval, academic self-esteem, and alienation did not reach adequate average responses in terms of their effect (a 4 or greater average score of "agree" was intended for most, or in the case of alienation, less than 2 for "disagree").

In discussing the potential for measuring association between attendance and positive interdependence scores, it was advised that the effect size of variance in attendance would be too narrow to produce the anticipated results; should the interest in positive interdependence as a cofactor remain, future iterations of this study must look toward methods that will enable effective measurement.

\section{Discussion}

The short range of data, lack of controlled condition, inability to pretest, and vast array of undiscussed factors could have influenced attendance in the students' environments. Still, as the world of education moves fast, and results were initially positive, it is worth pursuing these cooperative curricular changes onward, hoping to tease out results while ultimately aiming to give students a stronger, more industry-representative learning context.

The following results deserve attention:

- Lack of significance is a good sign for steady results, but does not represent ideal effect sizes, and vice versa. These attributes should be redesigned for separately in the future.

- Ideal effects were found in many positive interdependence subscales, but not in attendance and some key subscales, such as alienation being sorely middling.

- Data collected on reasons for attendance and non-attendance will be critical to examine.

- In-person learning was the focus, but transferring cooperative effects to remote learning is contemporarily important, both for accessibility and real industrial practices.

Although lack of significance indicates that the initial goal was met-to simulate cooperative group work in individual-focused portions of the introductory game development curriculumthese matched conditions are not necessarily at favorable or ideal levels of performance.

Attendance, for instance, was proportionally steadied, but the quantity of attendance did not quite achieve that of F2017's group work session, the current ideal.

Cooperative learning and achieving for social approval both increased significantly in the second half of the semester, which is to be expected when engaging group work, but fails the intent of this research procedure - ideally, such high survey scores would be achieved beginning in the first half of the semester and maintained into the second with little variance, which would suggest that the Co-Op activities in the individual-focused portion of the semester were effectively cultivating positive interdependence like full group work. On the other hand, cooperative learning scores were at a favorably high value regardless (well above 4.0 average, students "Agree"). 
Alienation survey scores were highly similar across both semesters (mean difference between the first and second half was an increase of 0.02), which does meet the purpose of the project, but the average survey scores around 2.5 (between students categorically "Disagreeing" or "Neither Agreeing nor Disagreeing" that they felt overall alienated in the class) are not desirable. It is understood that described feelings of isolation and/or lack of participation can undercut contrasting successes in positive interdependence, so reducing scores for this subfactor should be prioritized in future iterations, even if uneven across individual and group-based activity.

With these subscales' data in mind, it is apparent that significance and survey scores present a different image holistically than individually. Wholly, consistency was measured somewhat by way of lack of significant difference, but such probabilities are weak evidence on their own, especially when effectiveness is called into question.

Additional data collected but not yet rigorously analyzed includes categorical questions of students' reasons for attendance [5] surveyed on week 15, as well as general weekly surveys created for operational purposes. From a cursory glance at the week 15 attendance surveys, students reported on average that they did not skip due to disliking the course content or instructors, but for legitimate obstructions, such as family emergencies, physical and mental illness. One exceptional reason was the ability to receive the content outside of the lab or lecture; all content was accessible asynchronously through Purdue University's Learning Management System at the time, Blackboard. The instructors see this as a net positive.

Though many unknowns are common to appear in educational research, game dev instructors at Purdue are interested in exploring cross-class effects, how specialized courses may influence CGT Game Dev I. Students often dedicate a focus in animation, user experience, programming, or other trades, then bring them into game development, much like game dev as a career.

Further, if the data of these subscales highlights continual success in some, but not all subscales, participating researchers may look forward to developing a new construct off the basis of positive interdependence and its theoretical grounds.

It is recommended that those interested in this research seek to introduce and maintain other data collection methods to sharpen interpretations of positive interdependence scoring, and improve the width of attendance data sets such that there is enough variance to statistically analyze associations with a valuable effect size.

Remote and outsourced game development jobs do exist [23], [27], which may not align with this study's focus and background on in-situ cooperation. Directing attention to cultivating cooperation remotely is relevant at the time of this paper's creation, with the COVID-19 virus leading to a great number of schools and companies transitioning to remote work very suddenly [28], [29]. Those interested may follow the pursuit of game dev instructors livestreaming and analyzing their office hours [30] and the transferrable values of face-to-face contact in general [31]. 


\section{References}

[1] J. M. Braxton, et al, Rethinking college student retention, Hoboken: John Wiley \& Sons, Inc., 2013. [E-book] Available:

https://ebookcentral.proquest.com/lib/purdue/detail.action?docID=1495626 [Accessed Aug. 4, 2019]

[2] M. Deutsch, "A theory of cooperation and competition," Human Relations, vol. 2, pp. 129152, 1949. [Accessed Oct. 7, 2019]

[3] D. W. Johnson, and R. Johnson, "Student motivation in co-operative groups: Social interdependence theory," in Cooperative Learning: The Social and Intellectual Outcomes of Learning in Groups, A. Ashman and R. Gillies, Eds. Routledge, pp. 137-171, Sept. 25, 2003. [E-book] Available:

https://ebookcentral.proquest.com/lib/purdue/reader.action?docID=181919\&ppg=153

[Accessed Aug. 5, 2019]

[4] R. Erdei, B. E. McCord, and D. M. Whittinghill, "Unreal collaboration: exploring the use of formal collaborative learning strategy in games development coursework," in ASEE 2019 Annual Conference, Tampa, FL, USA, June 15-19, 2019. Accessed Aug. 25, 2019 [Online] Available: https://peer.asee.org/unreal-collaboration-exploring-the-use-of-formalcollaborative-learning-strategy-in-games-development-coursework.pdf

[5] R. Kottasz, "Reasons for student non-attendance at lectures and tutorials: An analysis," Investigations in University Teaching and Learning, vol. 2, no. 2, pp. 5-16, 2005. [Online] Available: http://repository.londonmet.ac.uk/172/ [Accessed Sept. 15, 2019]

[6] C. Paisey and N. J. Paisey, "Student attendance in an accounting module - reasons for nonattendance and the effect on academic performance at a Scottish University," Accounting Education, vol. 13, no. 1, pp. 39-53, 2004. [Online] Available: https://doi.org/10.1080/0963928042000310788 [Accessed Sept. 15, 2019]

[7] G. Lyubartseva, and U. P. Mallik, "Attendance and student performance in undergraduate chemistry courses," Education, vol. 133, no. 1, pp. 31-34, Sept. 22, 2012. [Online]

Available:

http://search.ebscohost.com.ezproxy.lib.purdue.edu/login.aspx?direct=true \&db=aph\&AN= 79776628\&site=ehost-live [Accessed August 4, 2019]

[8] D. R. Marburger, "Does mandatory attendance improve student performance?" The Journal of Economic Education, vol. 37, no. 2, pp. 148-155, Aug. 7, 2010. [Online] Available: https://doi.org/10.3200/JECE.37.2.148-155 [Accessed Sept. 15, 2019]

[9] J. L. Snyder, J. E. Lee-Partridge, A. T. Jarmoszko, O. Petkova, and M. J. D’Onofrio, “What is the influence of a compulsory attendance policy on absenteeism and performance?" 
Journal of Education for Business, vol. 89, no. 8, pp. 433-440, Nov. 4, 2014. [Online] Available: https://doi.org/10.1080/08832323.2014.933155 [Accessed Sept. 15, 2019]

[10] J. Reimer, "Cross-platform game development and the next generation of consoles." Ars Technica.com, Nov. 7, 2005. [Online] Available: https://arstechnica.com/features/2005/11/crossplatform/ [Accessed Sept. 21, 2019]

[11] S. Asch, Social psychology. Englewood Cliffs, NJ: Prentice-Hall, 1952.

[12] E. Wenger, Communities of practice: Learning, meaning, and identity. New York, NY: Cambridge University Press, 1998.

[13] J. Lave, and E. Wenger, Situated learning: Legitimate peripheral participation, New York, NY: Cambridge University Press, 1991. [Online] Out of print: http://dx.doi.org/10.1017/CBO9780511815355 [Accessed Aug. 5, 2019]

[14] E. Wenger-Trayner, "Communities of practice: A brief introduction. STEP Leadership Workshop, pp. 1-7, Oct. 20, 2011. [Online] Available: http://wengertrayner.com/introduction-to-communities-of-practice/ [Accessed Aug. 5, 2019]

[15] V. Tinto, "Dropout from higher education: A theoretical synthesis of recent research," Review of Educational Research, vol. 45, no. 1, pp. 89-125, 1975. [Online] Available: https://doi.org/10.1177/0092055X15603429 [Accessed Sept. 23, 2019]

[16] V. Tinto, (1986). "Theories of student departure revisited," in Higher education: A handbook of theory and research (Vol. 2), J. Smart, Ed. New York: Agathon, 1986, pp. 359-384.

[17] V., Tinto, Leaving college: Rethinking the causes and cures of student attrition (2nd ed.). Chicago, IL: University of Chicago Press, 1993. [Online] Available: https://ebookcentral.proquest.com/lib/purdue/detail.action?docID=3038692 [Accessed Sept. 23, 2019]

[18] K. F. Osterman, "Students' need for belonging in the school community," Review of Educational Research, vol. 70, no. 3, pp. 323-367, 2000. [Online] Available: https://doi.org/10.2307/1170786 [Accessed Aug. 25, 2019]

[19] D. Johnson, and R. Johnson, "New developments in social interdependence theory," Genetic, Social, and General Psychology Monographs, vol. 131, no. 4, pp. 285-358, Nov. 2005. [Online] Available: https://doi.org/10.3200/MONO.131.4.285-358 [Accessed Aug. 5, 2019]

[20] D. W. Johnson, and R. T. Johnson, "The use of cooperative procedures in teacher education and professional development," Journal of Education for Teaching, vol. 43, no. 3, pp. 284295, July 2017. [Online] Available: https://doi.org/10.1080/02607476.2017.1328023 [Accessed Sept. 30, 2019] 
[21] V. D. Tran, "Does cooperative learning increase students' motivation in learning?" International Journal of Higher Education, vol. 8, no. 5, pp. 12-20, July 24, 2019. [Online] Available: https://doi.org/10.5430/ijhe.v8n5p12 [Accessed Nov. 25, 2019]

[22] N. Rivera, "Cooperative learning in a community college setting: developmental coursework in mathematics,” Ph.D. dissertation, Dept. Edu., Arizona State Univ., Tempe, AZ, Apr. 2013. Retrieved from ProQuest LLC (3558669). [Online] Available: https://search.proquest.com/docview/1351960142?accountid=13360 [Accessed Sept. 30, 2019]

[23] G. Coker and A. Lackey. "Ori and the Blind Forest: Sonic polish through distributed development." YouTube.com, 2016. [Online] Available: https://youtu.be/_aQ05AP8MV8?t=425 [Accessed Mar. 18, 2020]

[24] D. W. Johnson, R. Johnson, and D. Anderson, "Social interdependence and classroom climate. Journal of Psychology, vol. 114 no. 1, pp. 135-142, May 1, 1983. [Online] Available: https://search.proquest.com/docview/1290613928/fulltextPDF/C19FC3A86B594317PQ/1? accountid=13360 [Accessed Aug. 14, 2019]

[25] A. Voight, and T. Hanson, Summary of existing school climate instruments for middle school: San Francisco, CA, USA: REL West at WestEd, 2012. [Online] Available: https://files.eric.ed.gov/fulltext/ED566402.pdf [Accessed Aug. 24, 2019]

[26] P. C. Abrami and B. Chambers, "Positive social interdependence and classroom climate," Genetic, Social \& General Psychology Monographs, vol. 120, no. 3, pp. 329-346, August 1994. [Online]. Available:

http://search.ebscohost.com.ezproxy.lib.purdue.edu/login.aspx?direct=true \&db=aph\&AN= 9409082583\&site=ehost-live [Accessed Aug. 14, 2019].

[27] Blur Studio. “About Blur Studio.” Blur.com. [Online] Available: http://www.blur.com/about [Accessed Mar. 18, 2020]

[28] J. Hadden, L. Casado, and T. Sonnemaker, "Oracle, Apple, Google, and Amazon are among the largest global companies who have restricted travel or asked their employees to work remotely as a precaution against the novel coronavirus. Here's the full list," Business Insider.com, Mar. 12, 2020. [Online] Available: https://www.businessinsider.com/companies-asking-employees-to-work-from-home-dueto-coronavirus-2020 [Accessed Mar. 18, 2020]

[29] A. McAloon. "Ubisoft, EA, Bethesda, and more enact remote working policies due to COVID-19.” Gamasutra.com, Mar. 18, 2020. [Online] Available: https://www.gamasutra.com/view/news/359726/Ubisoft_EA_Bethesda_and_more_enact_r emote_working_policies_due to_COVID19.php [Accessed Mar. 18, 2020] 
[30] T. Faas, L. Dombrowski, A. Young, and A. D. Miller, "Watch me code: Programming mentorship communities on Twitch.tv," in Proceedings of the ACM on Human-Computer Interaction, November 2018, pp. 1-18. Accessed Mar. 4, 2020 [Online] Available: https://doi.org/10.1145/3274319

[31] E. Wenger-Trayner, and B. Wenger-Trayner, (2014, July 22). "I'll take you with me...", Wenger-Trayner.com, July 22, 2014. [Online] Available: http://wenger-trayner.com/all/illtake-you-with-me/ [Accessed Sept. 30, 2019] 